\title{
ВЛИЯНИЕ ЭФФЕКТА ГЛУБОКОЙ МЕХАНОСОРБЦИИ УГЛЕКИСЛОГО ГАЗА НА РЕАКЦИОННУЮ СПОСОБНОСТЬ НЕФЕЛИНА И МАГНЕЗИАЛЬНО-ЖЕЛЕЗИСТОГО ШЛАКА ПРИ ВЗАИМОДЕЙСТВИИ С ВОДОЙ
}

\author{
Калинкин А.М., Гуревич Б.И., Калинкина Е.В., Залкинд О.А., Серова Е.С.
} Институт химии и технологии редких элементов и минерального сырья им. И.В. Тананаева КНЦPAH, Anamumbl,kalinkin@chemy.kolasc.net.ru

\section{Ввведение}

Измельчение минералов является важнейшей операцией, широко используемой как при подготовке проб для анализа, так и в крупномасштабных процессах переработки руд и рудных концентратов, а также в производстве различных строительных материалов. Интенсивное развитие потребностей в тонкодисперсных материалах повлекло необходимость создания высокоэнергонапряженных измельчительных аппаратов, среди которых наиболее эффективными являются центробежно-планетарные мельницы. Однако их использование приводит к настолько значительным изменениям в обрабатываемых веществах, что реализуется особый класс химических процессов - механохимических, которые при условии понимания механизмов протекающих реакций можно целенаправленно применять для повышения реакционной способности измельчаемых веществ и улучшения свойств получаемых на их основе материалов [3].

Известно, что газовая среда, в которой проводится механоактивация (МА), может значительно влиять на свойства получающихся порошков [4]. Ранее обнаружено, что при продолжительном истирании Са- и $\mathrm{Mg}$-содержащих силикатов, таких как диопсид $\mathrm{CaMgSi}_{2} \mathrm{O}_{6}$, волластонит $\mathrm{CaSiO}_{3}$ и другие одновременно со структурными нарушениями происходит их глубокая карбонизация за счет взаимодействия с углекислым газом воздуха [7]. Эффект карбонизации усиливается при МА в атмосфере $\mathrm{CO}_{2}$ [2]. Молекулы диоксида углерода поглощаются измельчаемыми минералами в виде карбонатных ионов, предположительно ассоциированных с катионами двух- и одновалентных металлов. Следует отметить, что обнаруженный эффект связан не с поверхностной хемосорбцией, а с ранее неизвестным явлением массированного проникновения диоксида углерода в наружные аморфизированные слои минерала (содержание $\mathrm{CO}_{2}$ в механически активированных образцах может достигать 20 мас. \%). Этот эффект можно использовать для целенаправленной модификации наружных слоев частиц силикатов с целью повышения их реакционной способности, в том числе при твердении вяжущих. В данной работе рассмотрено влияние механохимической карбонизации алюмосиликата натрия и калия - нефелина и магнезиально-железистого шлака на их реакционную способность при взаимодействии с водой, что важно для прогнозирования процессов гидратации вяжущих материалов с участием этих компонентов.

\section{Экспериментальная часть}

В работе использовали гранулированный магнезиально-железистый шлак комбината «Печенганикель» Кольской ГМК и нефелиновый концентрат (НК) производства ОАО «Апатит». Химический состав шлака (мас. \%): $\mathrm{SiO}_{2} 36.87, \mathrm{Al}_{2} \mathrm{O}_{3}$ 5.44, $\mathrm{FeO} 31.08, \mathrm{Fe}_{2} \mathrm{O}_{3} 2.47, \mathrm{CaO} 2.11, \mathrm{MgO} 11.92$, $\mathrm{Na}_{2} \mathrm{O} 1.18, \mathrm{~S} \mathrm{0.76}$, Со 0.10, $\mathrm{Ni} 0.24, \mathrm{Cu} 0.16$. Химический состав НК (мас. \%): $\mathrm{SiO}_{2} 43.37, \mathrm{Al}_{2} \mathrm{O}_{3} 29.48$, $\mathrm{Fe}_{2} \mathrm{O}_{3} 2.90, \mathrm{CaO} 0.84, \mathrm{MgO} 0.27,\left(\mathrm{Na}_{2} \mathrm{O}+\mathrm{K}_{2} \mathrm{O}\right) 21.8, \mathrm{~S} 0.71, \mathrm{TiO}_{2} 0.27, \mathrm{P}_{2} \mathrm{O}_{5} 0.03$. Минеральный состав компонентов, мас. \%: шлак - магнезиально-железистое стекло 95-98, кристаллическая фаза (скелетные кристаллы оливина) 2-5, рудные минералы 1-3; НК - нефелин 75-80, полевые шпаты 8-16, вторичные минералы по нефелину 1.5-10, эгирин 1.5-5, титаномагнетит 0.4-0.6, апатит 0.2-0.8, титанит 0.5-1.0.

МА шлака и НК проводили в лабораторной центробежно-планетарной мельнице АГО-2 и в виброистирателе 75Т-ДРМ в воздушной среде и в атмосфере углекислого газа. Образцы шлака и НК выщелачивали дистиллированной водой с перемешиванием на магнитной мешалке. Содержание $\mathrm{CO}_{2}$ в механоактивированных образцах определяли с помощью анализатора ELTRA CS-2000. ИК спектры снимались на Фурье ИК спектрометре Nicolet 6700 FTIR в таблетках бромида калия. 
Удельную поверхность определяли методом низкотемпературной адсорбции азота с помощью анализатора Flow-Sorb II 2300 (Micromeritics).

\section{Результаты и их обсуждение}

При механосорбции углекислого газа минералами, а также при его растворении в силикатных расплавах чувствительным инструментом, характеризующим конфигурацию образующихся карбонатных ионов, зависящую от их окружения, является ИК спектроскопия. Характерной особенностью механохимически карбонизированных силикатов является появление в ИК спектрах двойного пика в области 1600-1350 $\mathrm{cm}^{-1}$, отвечающего $v_{3}$ валентным колебаниям $\mathrm{CO}_{3}^{2-}$ группы с пониженной симметрией (связи С-О неэквивалентны) [7].

На рисунках 1 а и 1 б приведены ИК спектры образцов НК и шлака до и после МА в атмосфеpe $\mathrm{CO}_{2}$. МА НК проводили в виброистирателе в течение 250 мин, а МА шлака - в мельнице АГО-2 в течение 30 мин. Содержание $\mathrm{CO}_{2}$ в механоактивированных НК и шлаке составило 1.88 мас. \% и 4.67 мас. \% соответственно. Расщепление карбонатной полосы для нефелина $(\mathrm{Na}, \mathrm{K}) \mathrm{AlSiO}_{4}\left(\sim 190 \mathrm{~cm}^{-1}\right)$ заметно больше, чем в случае шлака, основу которого составляет оливиновое стекло $(\mathrm{Mg}, \mathrm{Fe})_{2} \mathrm{SiO}_{4}$ $\left(\sim 120 \mathrm{~cm}^{-1}\right)$. Это свидетельствует о значительно большем искажении $\mathrm{CO}_{3}{ }^{2}$ группы в аморфизированной алюмосиликатной матрице нефелина.
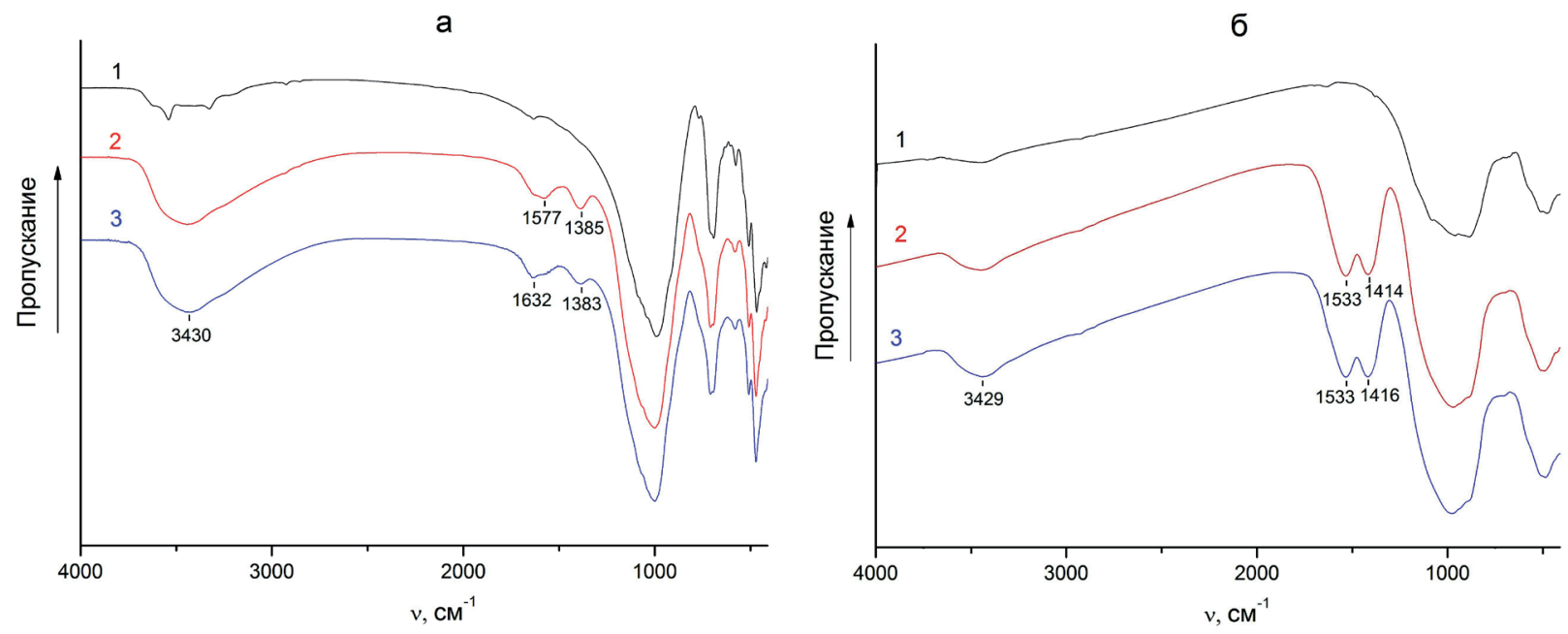

Рис. 1. ИК спектры НК (а) и шлака (б):

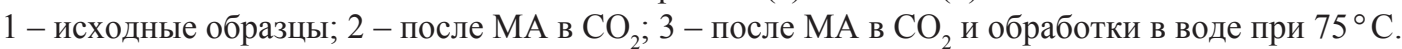

Ранее обнаружено, что наблюдается аналогия между механохимически карбонизированными силикатами и силикатными стеклами аналогичного состава, полученными быстрым охлаждением (закалкой) расплавов, содержащих растворенный $\mathrm{CO}_{2}$ [7]. Так, согласно литературным данным в ИК спектрах нефелиновых стекол, содержащих растворенный при высоких температуре и давлении диоксид углерода, присутствует весьма близкий по форме и положению двойной пик $\mathrm{CO}_{3}^{2-}$ группы с максимумами $\sim 1375 \mathrm{~cm}^{-1}$ и $\sim 1600 \mathrm{~cm}^{-1}$ [6] (ср. рис. 1 а, кривая 2). Этот пик заметно отличается по величине расщепления от соответствующего пика в спектрах оливин-мелилитовых стекол, который имеет максимумы в области 1530-1410 см ${ }^{-1}$ [5] (ср. рис. 1 б, кривая 2). Примечательно, что близкие состояния разупорядоченности кристаллической структуры силиката с внедренными карбонатными ионами достигаются столь разными путями: механической обработкой в энергонапряженных мельницах и за счет процессов, происходящих при высоких температурах и давлениях, соответствующих земной магме $\left(\mathrm{t} \sim 1500^{\circ} \mathrm{C}, \mathrm{P} \sim 1\right.$ ГПа).

Водную обработку указанных МА-образцов НК и шлака проводили при $75 \pm 3^{\circ} \mathrm{C}$ в течение 5 ч, т:ж=1:100. ИК спектры НК и шлака после обработки в $\mathrm{H}_{2} \mathrm{O}$ (рис. 1а и 16, кривые 3 ) свидетельствуют о том, что карбонатные группы весьма прочно связаны с минеральной матрицей. Для шлака ин- 
тенсивность, форма и положения максимумов расщепленной полосы $\mathrm{CO}_{2}^{2-}$ группы в результате обработки водой при $75^{\circ} \mathrm{C}$ фактически не изменились. В случае НК после взаимодействия с водой плечо одного из максимумов двойной полосы при $1577 \mathrm{~cm}^{-1}$ со стороны более коротких длин волн (рис. 1а, кривая 2) превратилось в пик при $1632 \mathrm{~cm}^{-1}$ (рис. 1а, кривая 3). Это указывает, вероятно, на гидратацию нефелина при водной обработке, поскольку область 1640-1630 см-1 соответствует деформационным колебаниям ОН-групп.

Одним из наиболее важных факторов, влияющих на твердение вяжущих, является степень перехода в жидкую фазу кремния и других компонентов, участвующих в образовании цементного камня. В таблице приведены результаты экспериментов по выщелачиванию исходного шлака и шлака после МА в течение 10 мин в мельнице АГО-2 в воздушной среде и в углекислом газе. Содержание $\mathrm{CO}_{2}$ в шлаке после МА в воздушной среде и в углекислом газе составило 0.12 мас. \% и 0.81 мас. \%, а удельная поверхность образцов - $1.94 \mathrm{~m}^{2} /$ и и $1.68 \mathrm{~m}^{2} / \Gamma$ соответственно. Выщелачивание проводили при $20 \pm 2{ }^{\circ} \mathrm{C}$ в течение 3 ч, т:ж=1:10. Полученную суспензию центрифугировали, содержание компонентов в жидкой фазе определяли методом масс-спектрометрии с индуктивносвязанной плазмой на приборе ELAN 9000 DRC-е.

Таблица. Состав и $\mathrm{pH}$ жидкой фазы после выщелачивания водой образцов исходного и механоактивированного шлака.

\begin{tabular}{|c|c|c|c|c|c|c|c|c|}
\hline Образец & $\mathrm{pH}$ & $\mathrm{MgO}$ & $\mathrm{SiO}_{2}$ & $\mathrm{Fe}$ & $\mathrm{Al}$ & $\mathrm{Co}$ & $\mathrm{Ni}$ & $\mathrm{Cu}$ \\
\hline исходный & 6.41 & 0.671 & 1.38 & 0.213 & 0.063 & 0.0013 & 0.028 & 0.025 \\
\hline МА в возд. & 8.78 & 19.80 & 2.70 & $<0.03$ & 0.330 & 0.0020 & 0.030 & 0.003 \\
\hline $\mathrm{MA} \mathrm{в} \mathrm{СО}_{2}$ & 8.64 & 36.50 & 4.80 & $<0.03$ & 0.170 & 0.0010 & 0.045 & 0.014 \\
\hline
\end{tabular}

Примечание: содержание компонентов приведено в мг/л.

МА шлака в воздушной среде и в $\mathrm{CO}_{2}$ резко увеличивает выщелачивание магния - его концентрация в растворе возрастает более чем на порядок (табл.). При этом $\mathrm{MA} \mathrm{в} \mathrm{CO}_{2}$ по сравнению с $\mathrm{MA} \mathrm{в}$ воздушной среде в отношении извлечения $\mathrm{Mg}$ эффективнее почти в два раза. Ионы $\mathrm{CO}_{3}^{2-}$, образующихся при механосорбции шлаком диоксида углерода, предположительно ассоциируются с магнием, что, вероятно, облегчает его переход в раствор в карбонатной форме. Степень извлечения компонентов зависит как от реакционной способности поверхности твердого вещества, так и от величины этой поверхности. После МА в воздушной среде удельная поверхность шлака несколько больше, чем после $\mathrm{MA} \mathrm{в} \mathrm{CO}_{2}$. Следовательно, механохимическая обработка в углекислом газе существенно повышает реакционную способность поверхности шлака.

МА в обеих средах также увеличивает в несколько раз выщелачивание кремния и алюминия, но извлечение железа после МА значительно снижается (табл.). С экологической точки зрения важно отметить, что МА не оказывает ощутимого влияния на выщелачивание $\mathrm{Cu}$, $\mathrm{Ni}$ и $\mathrm{Co}$, присутствующих в шлаке в сульфидной форме. Жидкая фаза после контакта с образцами МА-шлака, в отличие от исходного шлака, имеет щелочную реакцию (табл.), что обусловлено повышенным ионным обменом между катионами в составе механоактивированного шлака (прежде всего, магния) и протонами водной фазы. Очевидно, что кислотность среды является одним из определяющих факторов, влияющих на обнаруженные тенденции выщелачивания железа и цветных металлов из исходного и МА-шлака.

Результаты опытов по выщелачиванию НК, механоактивированного в течение 270 с в мельнице АГО-2 в воздушной среде и $\mathrm{CO}_{2}$, представлены на рис. 2. Содержание $\mathrm{CO}_{2}$ в НК после МА в воздушной среде и в углекислом газе равнялось 0.15 мас. \% и 0.38 мас. \%, а удельная поверхность образцов - $6.7 \mathrm{~m}^{2} / \Gamma$ и $7.6 \mathrm{~m}^{2} / \Gamma$ соответственно. Условия выщелачивания: температура $20 \pm 2{ }^{\circ} \mathrm{C}$, продолжительность 6 ч. В целом, даже с учетом несколько большей удельной поверхности НК после МА в $\mathrm{CO}_{2}$ по сравнению с МА в воздушной среде, полученные данные свидетельствуют о том, что МА в углекислом газе ускоряет выщелачивание основных компонентов нефелина в расчете на единицу поверхности, при этом извлечение кремния в водную фазу возрастает фактически на порядок (рис. 2). 


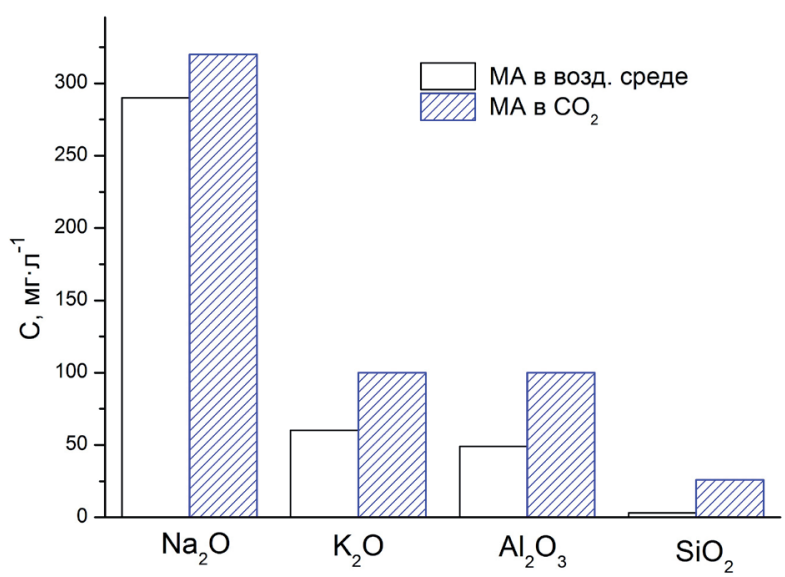

Рис. 2. Состав жидкой фазы после выщелачивания водой образцов НК, механоактивированного в воздушной среде и в $\mathrm{CO}_{2}$.
Таким образом, МА шлака и НК в атмосфере $\mathrm{CO}_{2}$, по данным ИК спектроскопии приводит к поглощению ими углекислого газа в виде карбонатных групп, конфигурация которых очень близка к конфигурации $\mathrm{CO}_{3}^{2-}$ групп, образующихся при растворении диоксида углерода в силикатных расплавах аналогичного состава при высоких температурах и давлениях. Карбонатные группы в составе механоактивированных силикатов достаточно устойчивы к водной обработке даже при повышенной температуре $\left(75^{\circ} \mathrm{C}\right)$. Вместе с тем, в сравнении с МА в воздушной среде, механохимическая карбонизация шлака и НК при МА в $\mathrm{CO}_{2}$ ощутимо интенсифицирует переход в жидкую фазу $\mathrm{Si}, \mathrm{Mg}$, $\mathrm{Na}$ и $\mathrm{K}$, что должно положительно влиять на протекание

гидратационных процессов при использовании этих компонентов в составе вяжущих. Как показано в работе [1], МА смеси НК и магнезиально-железистого шлака в атмосфере $\mathrm{CO}_{2}$ в сравнении с МА на воздухе способствует заметному увеличению прочности образцов, полученных с применением в качестве затворителя воды.

\section{Литература}

1. Гуревич Б.И., Калинкин А.М., Калинкина Е.В., Мазухина С.И., Тюкавкина В.В. Геополимерное вяжущее на основе механоактивированных композиций магнезиально-железистого шлака и нефелина // Перспективные материалы. 2015. № 3. С. 63-71.

2. Калинкин А.М., Политов А.А. Болдырев В.В., Калинкина Е.В., Макаров В.Н., Калинников В.Т. Эффект глубокой карбонизации диопсида при механической активации в среде $\mathrm{CO}_{2} / / / /$ Докл. РАН. Геохимия. 2001. T. 378. № 2. С. 233-237.

3. Аввакумов Е.Г. Механические методы активации химических процессов. Новосибирск. Наука. 1986. $305 \mathrm{c}$.

4. Ходаков Г.С. Сорбционная механохимия твердых неорганических материалов // Коллоидный журн. 1994. T. 56. № 1. С. 113-128.

5. Brey G. $\mathrm{CO}_{2}$ solubility and solubility mechanisms in silicate melts at high pressures // Contributions to Mineralogy and Petrology. 1976. V. 57. P. 215-221.

6. Brooker R.A., Kohn S.C., Holloway J.R., P.F. McMillan, M.R. Carroll. Solubility, speciation and dissolution mechanisms for $\mathrm{CO}_{2}$ in melts on the $\mathrm{NaAlO}_{2}-\mathrm{SiO}_{2}$ join // Geochimica et Cosmochimica Acta 1999. V. 63. P. 3549-3565.

7. Kalinkina E.V., Kalinkin A.M., Forsling W., Makarov V.N. Sorption of atmospheric carbon dioxide and structural changes of $\mathrm{Ca}$ and $\mathrm{Mg}$ silicate minerals during grinding: I. Diopside // International Journal of Mineral. Processiing. 2001. V. 61. P. 273-288. 